\title{
Covid-19: doctors in final trimester of pregnancy should avoid direct patient contact
}

\author{
Abi Rimmer
}

The BMJ

Women who are more than 28 weeks pregnant should avoid direct contact with patients-whether or not they could be infected with covid-19, says updated guidance. Those who are less than 28 weeks pregnant, however, can continue to work in patient facing roles provided they use the right personal protection equipment (PPE).

The advice comes from updated guidance from the Royal College of Obstetricians and Gynaecologists (RCOG), the Royal College of Midwives, and the Royal College of Paediatrics and Child Health.

It says that while it may not be possible for doctors before 28 weeks' gestation to completely avoid caring for patients with covid-19, risk assessments and the use of PPE will give them protection from infection.

"Some working environments, such as operating theatres, respiratory wards, and intensive care and high dependency units, carry a higher risk for pregnant women of exposure to the virus through the greater number of aerosol generating procedures performed," the guidance says.

"When caring for suspected or covid-19 patients all healthcare workers in these settings are recommended to use appropriate PPE. Where possible, pregnant women are advised to avoid working in these areas with suspected or covid-19 patients."

For pregnant women after 28 weeks' gestation, or with underlying health conditions such as heart or lung disease, a more precautionary approach is advised.

Women in this category should work from home where possible, avoid contact with anyone with symptoms of covid-19, and significantly reduce unnecessary social contact, the guidance says. "For many healthcare workers, this may present opportunities to work flexibly in a different capacity, for example by undertaking telephone or videoconference consultations, or taking on administrative duties."

Women who have chosen not to follow government advice and attend the workplace must not be deployed in roles where they are working with patients, it added. "Services may want to consider deploying these staff to support other activities such as education or training needs (such as in infection prevention and control or simulation)," the guidance said.

Edward Morris, president of the RCOG, said the college was aware that the current uncertainty about the risks posed by covid-19 to pregnant women and their babies was causing substantial difficulties and confusion for women, their families, and their employers.

"Therefore, we very much welcome this further guidance for pregnant healthcare workers which we have developed with the UK chief medical officers."

He added, "This will enable women and their employers to more effectively plan their working patterns and continue to make a valuable contribution to the workplace until the start of their maternity leave."

Morris said that the evidence base was growing rapidly and, when new information emerged, the college would give new advice through its guidance.

Royal College of Obstetricians and Gynaecologists. Coronavirus (COVID-19) infection in pregnancy: information for healthcare professionals (version 2). 13 March 2020. www. rcog.org.uk/globalassets/documents/guidelines/2020-03-21-covid19-pregnancy-guidance2118. pdf.

Published by the BMJ Publishing Group Limited. For permission to use (where not already granted under a licence) please go to http://group.bmj.com/group/rights-licensing/ permissions 